Revista de la red interuniversitaria de estudios sobre las literaturas rioplatenses contemporáneas en Francia

13 | 2015

Nuevas experiencias editoriales y literaturas

contemporáneas

\title{
Lírica asimetría
}

Luis Chitarroni

\section{OpenEdition}

Journals

Edición electrónica

URL: http://journals.openedition.org/lirico/2168

DOI: $10.4000 /$ lirico.2168

ISSN: 2262-8339

\section{Editor}

Réseau interuniversitaire d'étude des littératures contemporaines du Río de la Plata

Referencia electrónica

Luis Chitarroni, «Lírica asimetría », Cuadernos LIRICO [En línea], 13 | 2015, Puesto en línea el 15 diciembre 2015, consultado el 30 abril 2019. URL : http://journals.openedition.org/lirico/2168 ; DOI : $10.4000 /$ lirico.2168

Este documento fue generado automáticamente el 30 abril 2019.

\section{(c) $)(9)$}

Cuadernos LIRICO está distribuido bajo una Licencia Creative Commons Atribución-NoComercialSinDerivar 4.0 Internacional. 


\section{Lírica asimetría}

\section{Luis Chitarroni}

Hay una circunstancia en Peripecias del no a la que se asoman los poetas, los novelistas y los traductores. Propuesta la equidad temporal del Eclesiastés, puntuales el tiempo de abrazar y el de abstenerse. Las interrupciones ejercen su poder; mejor dicho, el magnetismo esquivo de la interrupción conquista de nuevo su ángulo de incidencia. Creemos a menudo que todas las tareas de este mundo estarán reunidas con el tiempo de su ejecución; sin embargo, los trabajos y los días -a partir de sínodos, no de Hesíodo-, se distancian cada vez más unos de los otros. Y terminamos haciendo el trabajo que nos prometimos evitar. Hoy, al despertar, me desmayé en mi conciencia. $Y$ así y más : me desperté y no era otro día. Suele notarse porque Heráclito sucedió a Hesíodo para criticarlo y hacer efectiva la indiferencia. El sueño y la vigilia están a mano, como la noche y el día. Si de veras fuéramos dioses : nuestros sueños serían como la vigilia de ustedes.

Sobre los basamentos y principios de mi novela Peripecias del no prefiero hablar ahora antes de callar para siempre (o por tiempo indeterminado, ya que soy tan capaz de canjear mis principios como Groucho Marx).

Gracias a la Biblioteca Nacional, tenemos ediciones (facsimilares) de las principales revistas literarias, y una que me sorprendió, en la medida en que comparte su diuturnidad con el periodo inicial de Ágrafa, la revista de mis Perips, fue Poesía Buenos Aires, que dirigía Raúl Gustavo Aguirre. Es de una asombrosa y estable calidad, con un repertorio de temas que no parece aventurarse más allá de la literatura alemana y francesa -afanándose de paso en convertir los poemas propios en una especie de traducciones aunque no lo sean, para que predomine una insipidez tan copiosa como fértil; y que entroniza, como debe ser, a los sujetos de sus permanentes (y hasta perdurables) veneraciones, como Rainer María Rilke, Albert Camus o René Char. Es cierto que esa regularidad, ese metódico repudio de la sorpresa alcanzan para implantar una melancolía inextinguible y para aprovecharse de la ausencia de color, no hablamos del -i benditos Soulages y Franz Kline!-, negro equivalente, rebosante de suposiciones y presunciones, sino sobre todo de combinaciones de sienas y ocres en la paleta. En realidad, compone una superficie menos aventurada y, por lo mismo, 
crédulamente aceptable de lo que suele sospecharse $\mathrm{y}$, hasta imaginarse, que una revista (argentina) tiene que ser. Involuntariamente, Ágrafa, la revista de mi invención, se le parecía.

La revelación de [algunas de] las hipótesis de mi novela, hipótesis tan inanes como sociológicas, poco puede conmover al lector ahora o antes, pero obedecieron a persuasiones no siempre súbitas del tiempo que me precedió ("ántumas", diría Alphonse Allais, en contraposición a "póstumas"), y viéndolas hoy en las amplias, sinuosas curvas que diseñan sus errores cartográficos en la pantalla, descartan de la conducta argentina la mayoría de las contorsiones y desvaríos jubilosos a las que sometí a mis personajes (poetas y narradores, a fin de cuentas). Como si por un túnel se pudiera desembocar a oscuras en un arrabal de aventuras arrepentidas de la prédica de los géneros de los setenta (ni gótico rioplatense ni doxie gongorism songorocosonguizado, ni -menos aun- alternativas tan dudosas del uso del policial (género sobrevalorado por excelencia), como penuria sin evaluación. Especie de Terminal ganadora de una competencia o certamen obliterado por la kermesse tremendista de la larga risa de todos esos años.

Después de años de concentración en Nero Wolfe y Lemmy Caution para desperdiciar en bandeja Venus Rattlesnake en Perips, otra cosa sería hablar de Inherent Vice, de Pynchon, donde el policial alcanzara su arco iris de gravedad.

Imaginar un conjunto o un tráfico de afinidades no muy electivas en torno a los caprichos de un cacique tiránico -Nicasio Urlihrt- excedió en Peripecias del no mi capacidad de un mantenimiento verosímil (y creo que el pretexto del diario se propuso atenuar esa falta de cálculo). Lo cierto es que los percances -las peripecias- de los personajes de la novela -Elena Siesta, Nicasio Urlihrt, Remo Scacchi, Oliverio Lester-, no siempre, me temo, caracterizados con la condición de ser memorables (o reducidos a no serlo por la suficiencia acústica del nombre), tienen para mí, que me permití la pereza adicional de abandonarlos, un relieve distinto que el que debe encargarse de darles el lector, tentado en una primera instancia, se supone, de seguirlos.

Son un elenco de cómicos de la lengua modelados a partir de desproporciones literarias, que actúan como pueden a partir de esa condición tan restrictiva, vigilando lo que no conocen. Por lo demás, tienen amparo para distribuir escasamente unos poemitas (recuerdo la sestina de ida y vuelta cercenada y un ensayo de soneto que se llama, creo, 'Los mandados'). $Y$ un poema que se aprovecha de un atril para mencionar el anticuado Étude sur les notes de passage, de Koechlin, artefacto tan anticuado hoy como muchas de las otras, transitorias fuentes.

En el curso de un despertar oblicuo, nada me arrepiente -soy un hombre de nervios, no de principios, como dice Joseph Brodsky (¿ citando a Akutagawa Ryunosuke ?)

La primera, hospitalaria versión de Perips, se llamaba Las equis distantes (contra ella reaccionaron todos los interlocutores que la oyeron mencionar), contenía una amplia sección -Aria del sorbetto- destinada y dispuesta a albergar [muchas] otras formas tan espiraladas y embrionarias [D'Arcy Thompson] como las que se interponían e intercalaban antes de que el prólogo de Perips se ocupara de olvidar su cometido. En cuanto a los géneros implicados en revista tan pródiga como Ágrafa, había también brevedades y narraciones que abovedaban el paso del tiempo, alguna tal vez con celo extremo. Cuando el control empezó a impacientarme y fastidiarme, tuve la ventaja de 
dar con esa cita de Giordano Bruno en donde dice que todos los sistemas cerrados tienden inevitablemente a la implosión, a la destrucción sistemática ; decidí entonces hacer estallar la estructura entera [me sobraba combustible] desde afuera y volver corriendo para quedarme adentro solo con las esquirlas, los harapos y las ruinas. No lo lamento, pero nunca más encontré la cita, que cuando leí la primera vez creí se dirigía directamente (no tengo problema con la megalomanía) a mí.

Nada resulta sencillo en el mundo de las apariencias, de modo que es admisible que lo sea menos en el mundo no exento de luz de la oscuridad literaria, arrogancia de arrastre menos innecesaria de lo que se sospecha. La lítote será nuestro guía, nuestra Beatrice, como para Mallarmé la destrucción. Por lo tanto, bastaría mencionar a Heráclito con menos frecuencia de lo que se lo menciona en tiempos de Poesía Buenos Aires -y eso era conducta impensable en Poesía Buenos Aires- para que su ausencia de color menguara la atractiva mística que establece en quienes no se detuvieron a estudiarlo (o sobre todo en quienes ni siquiera lo pensaron). Raúl Gustavo Aguirre, un Nurliht honesto, sin las miserias inherentes del Nurlihrt de Perips, no solo se dedicó a estudiarlo, como parecía ser el mandato de la época, puro Zeitgeist, sino que hasta revisó y corrigió (suponemos que en beneficio de sí mismo) los fragmentos que publicó con elegancia pero sin precisar la fuente, La razón ardiente en su volumen inaugural, en 1956 , dos años antes de que yo naciera.

Por supuesto que los personajes escritores de Perips se habían tomado el trabajo de ser mayores que yo, para que yo, mero pálpito, encontrara mi escena, mi teoría sexual infantil, mi pérdida del reino, y hasta algo que me hiciera creer -que me hace creerque custodio, insisto, cómico de la lengua, lo que no conozco.

En aquellos tiempos, Heráclito, si bien importaba poco de qué lengua era traducido, implicaba lo esencial, que es para todos nosotros la lengua que entendemos, la lengua materna con o sin adhesiones explícitas. Una mueca adicional añadía (añadiría) elegancia o displicencia (que vienen a ser lo mismo) al gesto. La intervención de corchetes y puntos suspensivos parece asegurar que se lo traduce de una tipografía a otra, nada más.

Cuando Glenn Gould, en su encarnación del crítico Karlheinz Kloppweisser tiene ocasión de descender a temas tan elevados como el silencio, afirma sin hesitación que el silencio de los músicos franceses es ornamental, a diferencia del de los alemanes, que es significativo. ¿ Fouré vs. Webern? La historia, como bien enseña Gibbon, es el gradus ad parnassum del estilo (lo corrobora Borges), el grado más alto del estilo, sometido, claro, al proverbial, providencial nacionalismo. Lo señala Borges, esta vez sí,

de una benéfica fuente francesa

que voy a abstenerme de mencionar.

Rumbo al polo, aquí empezaríamos a devorar los perros de nuestros trineos. G.D.

Los cabeceos regulares con que un oficio deroga o difiere sus responsabilidades son, en este caso, la débil calistenia hoy elegida. Abrir la herida de la edición en este punto es omitir el sabor a suela de su monotonía, de su rutina correctora, el rectorado de sombrías obligaciones dictatoriales que parecen haber restado cualquier atisbo lírico al demorado arte de editar.

En gran medida, la preferencia por un escritor que no necesita edición reemplaza un catálogo de rechazos o de conveniencias a la hora de repetir ciertos menesteres 
terrestres. P.M. Hubbard tiene una carrera restringida (1967-1978, más o menos), a la que dedicó una cuidadosa industria y un poderoso talento lírico. Hubbard había empezado como poeta (aunque no leí uno solo de sus poemas) en los años de juventud, algo que suele ser condenado a debut y discontinuidad, en el obituario común, tarde o temprano, de las solapas. No era necesario que viniera tan luego a "descubrirlo" yo en una editorial como La bestia equilátera, casi cincuenta años después de que publicara los primeros libros. Hay una persuasión tan inusual en esa prosa como la que podría descubrir un editor extranjero, que se jactara de leer bien el castellano, en los primeros cuatro o cinco libros (incluido Cien años) de García Márquez. Uno tuvo éxito ; el otro, no. ¿A qué se deben estas diferencias de conducta, excluidas las coartadas más atemorizadoras de la sociología (ateniéndonos a aquello que, nos gustaría, prevalece, el estilo) ?

Las novelas de Hubbard no solo no excluyen los factores más sombríos de las personalidades de los personajes (algo que de manera alguna puede atribuirse a un psicologismo "entrador") sino que a menudo la caracterización de la mayoría de ellos parece un acto de destreza o un exabrupto de la sintaxis, que a menudo provoca los periodos más excelsos con apenas un excedente de elegancia (pido perdón por las excesivas equis, menos distantes siempre de lo que sospecho). Si bien hay en unos cuantos (no tengo ganas a esta hora de comprobarlo : me consta que mi memoria para sostenerlo alcanza) la situación pareja-en-lugar-desconocido, con el agregado de un habitante-que-los-precede-como-agente-del-extrañamiento se repite, ese esquema es tan virtuoso como el que puede infundir, inculcar o instilar un tema musical a los valores y virtudes de las variaciones (pido consideración semejante para la concurrencia de tantas ves labiodentales, mal conocidas como cortas, ex uves).

Ahora bien, bastaría difundir el tema de la que más difiere para encontrar un motivo de exclusión, por lo menos entre sus coterráneos/coetáneos. En The Country of Again, Hubbard licencia el extrañamiento por sujeto y lo reemplaza por el extrañamiento de lugar. Hace que el protagonista -un inglés cabal del tipo ciudadano impertérritoregrese a Pakistán, al Pakistán hiriente de la post separación (partition, 1947), para que el complot y la gangrenada corrupción perceptible se ciernan sobre un ciudadano sobrecargado de honorables responsabilidades y lo precipiten al abismo de la angustia y los remordimientos concomitantes a la disolución del ser, a la desaparición consecuente y conspicua de su total entereza. Que al chauvinismo y jingoísmo inglés esta información -o exceso de información- le molestara, no es de extrañar, claro, aunque parte del amor por la verdad de la confesión lo deba también a cierto protestantismo accidental en ayunas.

No creo que la literatura solicite conspiración tan solemne, pero no descarto la hipótesis en nombre, precisamente, de la literatura. Sin embargo, si predominara el juicio estilístico, poco o nada podría importarnos la excepción. Cada uno de los libros de M.P. Hubbard, cada una de sus novelas manifiesta e implica una yuxtaposición de calidades igualmente precisas y universales ; enumerarlas equivaldría a hacer una lista de ejemplos que nadie está obligado a respetar como tales. Todo relato en ciernes aprendería mucho de lo que cada relato terminado de Hubbard es. Precisión y ambigüedad (total : son orillas opuestas), belleza de la operación en cada una de sus partes (de la frase inconclusa del diálogo al capítulo), terca resistencia del periodo a las comodidades que cobijan, tras una sentenciosa andadura, el repliegue decepcionante de un lugar común arrodillado ante el anhelado punto final. 
AUTOR

LUIS CHITARRONI

Escritor 